\title{
Kamikihito Ameliorates Lipopolysaccharide-Induced Sickness Behavior via Attenuating Neural Activation, but Not Inflammation, in the Hypothalamic Paraventricular Nucleus and Central Nucleus of the Amygdala in Mice
}

\author{
Ryota Araki, ${ }^{* a}$ Shoji Nishida, ${ }^{a}$ Yosuke Hiraki, ${ }^{a}$ Feng Li, ${ }^{b}$ Kinzo Matsumoto,${ }^{c}$ and Takeshi Yabe*,a \\ ${ }^{a}$ Laboratory of Functional Biomolecules and Chemical Pharmacology, Faculty of Pharmaceutical Sciences, Setsunan \\ University; 45-1 Nagaotoge-cho, Hirakata, Osaka 573-0101, Japan: ${ }^{b}$ Research Promotion Office, Institute of Natural \\ Medicine, University of Toyama; 2630 Sugitani, Toyama 930-0194, Japan: and ${ }^{c}$ Division of Medicinal Pharmacology, \\ Institute of Natural Medicine, University of Toyama; 2630 Sugitani, Toyama 930-0194, Japan.
}

Received September 14, 2015; accepted November 24, 2015

\begin{abstract}
Sickness behavior is a series of behavioral and psychological changes that develop in those stricken with cancers and inflammatory diseases. The etiological mechanism of sickness behavior is not known in detail, and consequently there are no established standard therapies. Kamikihito (KKT), a Kampo (traditional Japanese herbal) medicine composed of 14 herbs, has been used clinically to treat psychiatric dysfunction. Previously, we found that KKT ameliorated sickness behavior in mice inoculated with murine colon 26 adenocarcinoma cells. In this study, we examined the effects of KKT on bacterial endotoxin lipopolysaccharide (LPS)-induced sickness behavior in mice. The administration of LPS caused the emotional aspects of sickness behavior, such as loss of object exploration, social interaction deficit, and depressive-like behavior. LPS also induced mRNA expression for cyclooxygenase (COX)-2, interleukin (IL)-1 $\beta$ and IL-6, and increased the number of c-Fos immunopositive cells in the hypothalamus and amygdala. KKT ameliorated the behavioral changes and reversed the increases in c-Fos immunopositive cells in the two brain regions, but did not influence the mRNA expression. These results suggest that KKT ameliorates sickness behavior via the suppression of neural activation without anti-inflammatory effects, and that KKT has the potential to treat sickness behavior.
\end{abstract}

Key words Kamikihito; sickness behavior; lipopolysaccharide; hypothalamus; amygdala

Sickness behavior refers to a set of adaptive behavioral and psychological changes, such as fatigue, anhedonia, depression, anxiety, apathy and loss of appetite, that occur in patients with cancer or infections. ${ }^{1-3)}$ Several studies have shown that activation of the immune system based on increases in release of inflammatory cytokines is associated with sickness behavior, ${ }^{2,4-13)}$ but the etiological mechanism is not known in detail. Thus, there are no standard therapies for sickness behavior.

The mechanism of induction of sickness behavior by immune system activation has been examined in bacterial endotoxin lipopolysaccharide (LPS)-treated animal models. Administration of LPS induces neuroinflammation and neural activation in rodent brain, and causes sickness behavior. ${ }^{11,14)}$ Neural activation in the paraventricular nucleus (PVN) of the hypothalamus and the central nucleus of the amygdala $(\mathrm{CeA})$ and emotional aspects of behavioral changes such as depressive-like behavior, social behavior deficits and loss of interest continue for more than $24 \mathrm{~h}$ after LPS administration. ${ }^{14,15)}$ These studies suggest that neural activation of the PVN and $\mathrm{CeA}$ is involved in LPS-induced sickness behavior.

Kamikihito (KKT) is a Kampo (Japanese herbal) medicine is used clinically to treat psychiatric dysfunctions such as anxiety, insomnia, amnesia and depression. Pharmacological studies have shown that KKT is effective for behavioral abnormalities and cognitive dysfunction induced by beta-amyloid, methyl-beta-carboline-3-carboxylate, scopolamine, delta9-tetrahydrocannabinol, ovariectomy, and senescence, ${ }^{16-20}$ ) which suggests that KKT has an effect on the central nervous system (CNS). Recently, we found that KKT ameliorates emo- tional aspects of sickness behavior in murine colon 26 adenocarcinoma cells-inoculated mice. ${ }^{21)}$

In this study, we examined the effects of KKT on LPSinduced sickness behavior in mice, with the aim of evaluating the possible therapeutic utility of KKT in sickness behavior. To clarify the mechanism underlying the ameliorative effect of KKT on sickness behavior, we examined the effect of KKT on LPS-induced inflammation and neural activation in the hypothalamus and amygdala.

\section{MATERIALS AND METHODS}

Animals Experimental procedures concerning the use of animals were conducted according to the Guiding Principles for the Care and Use of Laboratory Animals approved by the Japanese Pharmacological Society and the committee for Ethical Use of Experimental Animals at Setsunan University. Every effort was made to minimize animal suffering and to reduce the number of animals used. Seven-week-old male ddY mice were obtained from Shimizu Laboratory Supplies Co., Ltd. (Kyoto, Japan) and housed in cages $(24 \times 17 \times 12 \mathrm{~cm})$ in groups of 5 animals under controlled environmental conditions $\left(23 \pm 1{ }^{\circ} \mathrm{C} ; 12: 12\right.$-h light-dark cycle, humidity of $55 \%$, food and water ad libitum) for 1 week before use in experiments. We used different mice in each experiment.

Drug Treatments LPS (from Escherichia coli O127:B8; Sigma, St. Louis, MO, U.S.A.) was dissolved in saline $(0.9 \%$ (w/v) solution of $\mathrm{NaCl}$ ) and injected intraperitoneally (i.p.) $2 \mathrm{~h}$ before decapitation for mRNA measurement or $24 \mathrm{~h}$ before 
behavioral tests or decapitation for immunohistochemistry. The component herbs of KKT were indicated in Table 1. The Kampo formula was decocted with $600 \mathrm{~mL}$ of distilled water until the volume was reduced to half. The extract was immediately filtrated through filter paper in vacuo. The filtrate was lyophilized and the yield of KKT extract was approximately $27 \%$ of the herbal mixture, based on its dry weight. KKT was dissolved in distilled water and injected orally $1 \mathrm{~h}$ before LPS administration. All drugs were injected at a fixed volume of $10 \mathrm{~mL} / \mathrm{kg}$ body weight. To identify the chemical constituents of KKT extract, liquid column chromatography-mass spectrometry analyses were performed as described in supplementary materials.

Object Exploration Test Each mouse was habituated in an observation cage $(24 \times 17 \times 12 \mathrm{~cm})$ for $15 \mathrm{~min}$. After the habituation period, a novel object (a wooden ball of diameter $5 \mathrm{~cm}$ ) was placed in the center of the cage and behaviors were videotaped for $5 \mathrm{~min}$. The duration of object exploratory behavior (sniffing or licking the wooden ball) was measured.

Social Interaction Test A ddY mouse pretreated with drugs and an unfamiliar 8-week-old male ddY mouse were placed in a neutral cage $(24 \times 17 \times 12 \mathrm{~cm})$ and behaviors were videotaped for $20 \mathrm{~min}$. The total duration of social behaviors (sniffing, licking and following the unfamiliar mouse) of the pretreated mouse was measured.

Forced Swim Test Mice were individually placed in a polymethylpentene beaker (height $27 \mathrm{~cm}$, diameter $18 \mathrm{~cm}$ ) containing $25 \pm 1^{\circ} \mathrm{C}$ water of depth $13 \mathrm{~cm}$. The performance of the mice for $6 \mathrm{~min}$ in the swimming session was videotaped. The total duration of immobility was measured in the final $4 \mathrm{~min}$ of the 6-min test session.

Locomotor Activity Locomotor activity was measured using ANY-maze video tracking software (Stoelting Co.,
Wood Dale, IL, U.S.A.). Each mouse was placed in a novel opaque polyvinyl chloride cage $\left(40 \times 25 \times 30 \mathrm{~cm}^{3}\right)$. The behaviors of mice were videotaped for $30 \mathrm{~min}$ and the total distance traveled was analyzed.

Quantitative Real-Time Polymerase Chain Reaction (PCR) Total RNA was isolated from the hypothalamus and amygdala with TRIzol reagent (Invitrogen, Carlsbad, CA, U.S.A.). Total RNA $(1 \mu \mathrm{g})$ was used to perform reverse transcription with ReverTra Ace (Toyobo, Osaka, Japan). Quantitative real-time PCR was performed using a Thermal Cycler Dice Real Time System Single (TaKaRa Bio Inc., Shiga, Japan) and the primers indicated in Table 2. Changes in gene expression were calculated relative to the endogenous $\beta$-actin standard.

c-Fos Immunohistochemistry The c-Fos immunohistochemistry was performed as previously described. ${ }^{15)}$ Briefly, mice were anesthetized and perfused transcardially with saline, followed by a solution of $4 \%$ paraformaldehyde. The brain was fixed with $4 \%$ paraformaldehyde over $2 \mathrm{~d}$. Serial $50-\mu \mathrm{m}$ thick coronal sections containing the PVN $(-0.8$ to $-1.0 \mathrm{~mm}$ with respect to the bregma) and $\mathrm{CeA}(-1.0$ to $-1.2 \mathrm{~mm}$ with respect to the bregma) were cut using a microslicer (DTK-1000, Dosaka EM Co., Ltd., Kyoto, Japan). The free-floating sections were subjected to immunostaining analysis using an anti-c-Fos rabbit polyclonal primary antibody (1 : 20000 dilution; Calbiochem, San Diego, CA, U.S.A.), a biotinylated anti-rabbit immunoglobulin $\mathrm{G}(\mathrm{IgG})$ secondary antibody (1:200 dilution; Vector Laboratories, Burlingame, CA, U.S.A.) and avidin-biotin-horseradish peroxidase complex (Vectastain ABC kit; Vector Laboratories). Brown cytosolic products were obtained by reaction with 3,3'-diaminobenzidine (Sigma, St. Louis, MO, U.S.A.). The number of c-Fospositive nuclei were counted manually in three independent

Table 1. The Component Herbs of Kamikihito

\begin{tabular}{|c|c|c|c|}
\hline The component herbs & The manufacturer & Lot No. & Amount \\
\hline Ginseng Radix & Uchida Wakan-yaku Co., Ltd., Tokyo, Japan & 00F1204 & $3.0 \mathrm{~g}$ \\
\hline Atractylodis Rhizoma & Tochimoto Tenkaido Co., Ltd., Osaka, Japan & 009313005 & $3.0 \mathrm{~g}$ \\
\hline Poria & Tochimoto Tenkaido Co., Ltd., Osaka, Japan & 00951510016 & $3.0 \mathrm{~g}$ \\
\hline Zizyphi Semen & Tochimoto Tenkaido Co., Ltd., Osaka, Japan & 021110007 & $3.0 \mathrm{~g}$ \\
\hline Longan Arillus & Tochimoto Tenkaido Co., Ltd., Osaka, Japan & 022813003 & $3.0 \mathrm{~g}$ \\
\hline Bupleuri Radix & Tochimoto Tenkaido Co., Ltd., Osaka, Japan & P011304241 & $3.0 \mathrm{~g}$ \\
\hline Astragali Radix & Tochimoto Tenkaido Co., Ltd., Osaka, Japan & 001013005 & $3.0 \mathrm{~g}$ \\
\hline Angelicae Radix & Tochimoto Tenkaido Co., Ltd., Osaka, Japan & P011212271 & $2.0 \mathrm{~g}$ \\
\hline Gardeniae Fructus & Tochimoto Tenkaido Co., Ltd., Osaka, Japan & 004613004 & $2.0 \mathrm{~g}$ \\
\hline Polygalae Radix & Tochimoto Tenkaido Co., Ltd., Osaka, Japan & 001410002 & $2.0 \mathrm{~g}$ \\
\hline Zizyphi Fructus & Uchida Wakan-yaku Co., Ltd., Tokyo, Japan & 0301163 & $2.0 \mathrm{~g}$ \\
\hline Glycyrrhizae Radix & Uchida Wakan-yaku Co., Ltd., Tokyo, Japan & $00 \mathrm{~F} 3255$ & $1.0 \mathrm{~g}$ \\
\hline Saussureae Radix & Tochimoto Tenkaido Co., Ltd., Osaka, Japan & 010513001 & $1.0 \mathrm{~g}$ \\
\hline Zingiberis Rhizoma & Tsumura \& Co., Tokyo, Japan & D41821 & $0.5 \mathrm{~g}$ \\
\hline
\end{tabular}

Total $31.5 \mathrm{~g}$

Table 2. List of Primer Sequences Used in Quantitative Real-Time PCR

\begin{tabular}{lcc}
\hline \hline mRNA & Forward primer sequence $\left(5^{\prime}\right.$ to $\left.3^{\prime}\right)$ & Reverse primer sequence $\left(5^{\prime}\right.$ to $\left.3^{\prime}\right)$ \\
\hline COX-2 & GGCCATGGAGTGGACTTAAA & GGGATACACCTCTCCACCAA \\
IL-1 $\beta$ & TGTGAAATGCCACCTTTTGA & CAGGTCAAAGGTTTGGAAGC \\
IL-6 & GTTCTCTGGGAAATCGTGGA & TTCTGCAAGTGCATCATCGT \\
\hline
\end{tabular}


sections using a microscope (IX71, Olympus, Tokyo, Japan) with a CCD camera (VB-7010, Keyence, Osaka, Japan), and determined in a $500 \times 500 \mu \mathrm{m}^{2}$ area. The mean of this average across three sections was calculated for each mouse.

Statistical Analysis All data are expressed as the mean \pm standard error of the mean (S.E.M.). Data for behavioral tests and immunohistochemistry were analyzed using oneway ANOVA followed by a Tukey-Kramer post-hoc test. Data for mRNA expression were analyzed using two-way ANOVA followed by a Tukey-Kramer post-hoc test. Statistical analyses were performed using the software package, Statview 5.0 J for Apple Macintosh (SAS Institute Inc., Cary, NC, U.S.A.). A value of $p<0.05$ was considered to be significant.

\section{RESULTS}

Effect of KKT on LPS-Induced Behavioral Changes LPS $(500 \mu \mathrm{g} / \mathrm{kg})$ decreased the novel object exploration and social interaction, and increased the immobility time in the forced swim test. These LPS-induced behavioral changes were present at $24 \mathrm{~h}$ after LPS administration. KKT $(300 \mathrm{mg} / \mathrm{kg})$ significantly reversed the decrease in novel object exploration and social interaction, and the increase in immobility time in the forced swim test $\left(F_{3,28}=6.535, p=0.0017\right.$ for the object exploration test; $F_{3,33}=4.614, p<0.0084$ for social interaction test; $F_{3,31}=7.615, p=0.0006$ for the forced swim test). KKT $(1000 \mathrm{mg} / \mathrm{kg})$ also significantly reversed the decrease in novel object exploration and the increase in immobility time in the forced swim test, but did not influence the decrease in social interaction (Figs. 1A-C). Locomotor activity was not significantly changed at $24 \mathrm{~h}$ after LPS administration with or without treatment with $\operatorname{KKT}\left(F_{3,24}=0.770, p=0.5222\right)$ (Fig. 1D).

Effect of KKT on LPS-Induced Inflammation To investigate the mechanism underlying the influence of KKT on LPS-induced sickness behavior, we examined the effect of KKT on LPS-induced inflammation in the hypothalamus and amygdala. LPS $(500 \mu \mathrm{g} / \mathrm{kg})$ increased cyclooxygenase (COX)-2, interleukin (IL)- $1 \beta$ and IL-6 mRNA levels in the hypothalamus and amygdala at $2 \mathrm{~h}$ after LPS injection. In control mice, KKT had no effect or slightly decreased mRNA expression for inflammation-related genes in the hypothalamus and amygdala (Figs. 2A, B). Similarly, KKT did not affect the LPS-induced mRNA expression for inflammation-related genes in the hypothalamus or amygdala of sickness behavior model mice (Figs. 2A, B). Two-way ANOVA revealed main significant effects of LPS administration $\left(F_{(1,23)}=22.5\right.$, $p<0.0001$ for hypothalamic COX-2; $F_{(1,23)}=13.2, p<0.01$ for hypothalamic IL- $\beta ; \quad F_{(1,23)}=27.3, p<0.0001$ for hypothalamic IL-6; $F_{(1,23)}=22.6, p<0.001$ for amygdaloid COX-2; $F_{(1,23)}=19.3, \quad p<0.01$ for amygdaloid IL- $\beta ; \quad F_{(1,23)}=31.2$, $p<0.0001$ for amygdaloid IL-6) but not KKT treatment $\left(F_{(1,23)}=0.4, p>0.05\right.$ for hypothalamic COX-2; $F_{(1,23)}=0.7$, $p>0.05$ for hypothalamic IL- $1 \beta ; F_{(1,23)}=0.1, p>0.05$ for hypothalamic IL-6; $F_{(1,23)}=0.6, p>0.05$ for amygdaloid COX-2; $F_{(1,23)}=0.1, p>0.05$ for amygdaloid IL- $\beta ; F_{(1,23)}=1.4, p>0.05$ for amygdaloid IL-6), and there was no significant interaction
A

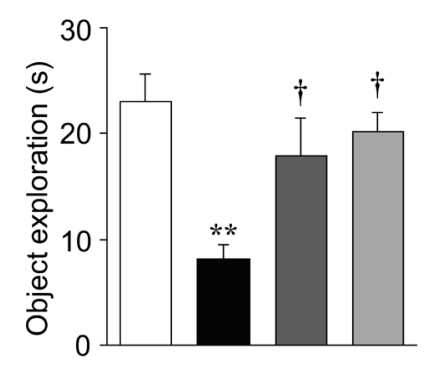

C

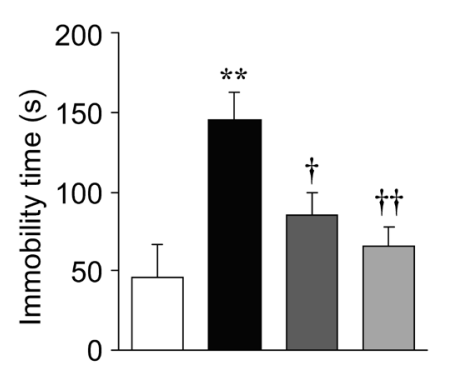

B

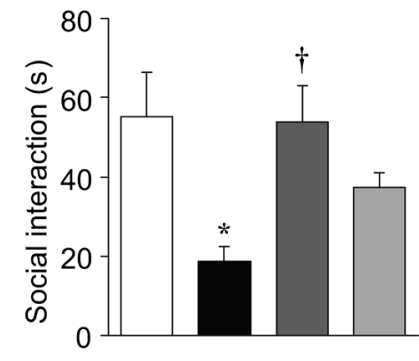

D

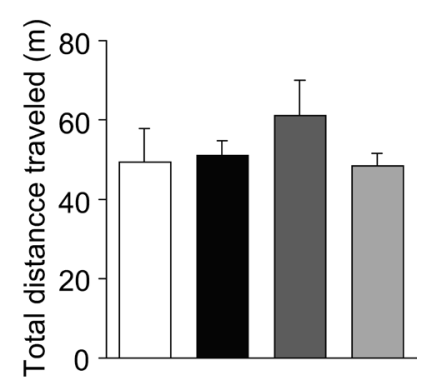

LPS KKT $(300 \mathrm{mg} / \mathrm{kg})$

LPS KKT (1000 mg/kg)

Fig. 1. Effect of KKT on LPS-Induced Behavioral Changes $24 \mathrm{~h}$ after LPS Administration

Mice were treated with LPS (500 $\mu \mathrm{g} / \mathrm{kg}) 24 \mathrm{~h}$ before the behavioral tests. (A) Effect of KKT on LPS-induced exploratory behavior deficits. Each mouse was placed in an observation cage $(24 \times 17 \times 12 \mathrm{~cm})$. After $15 \mathrm{~min}$, a novel object (a wooden ball of diameter $5 \mathrm{~cm}$ ) was placed in the center of the cage and the duration of object exploratory behavior (sniffing or licking the wooden ball) was measured. Values are expressed as the mean \pm S.E.M. of 8 mice. (B) Effect of KKT on LPS-induced social interaction deficits. A mouse pretreated with drugs and an unfamiliar mouse were placed in a neutral cage $(24 \times 17 \times 12 \mathrm{~cm})$ and videotaped for 20 min. The total duration of social interaction behavior of the pretreated mouse was analyzed. Values are expressed as the mean \pm S.E.M. of 9-10 mice. (C) Effect of KKT on LPS-induced depressive-like behavior in the forced swim test. The total duration of immobility was measured in the final $4 \mathrm{~min}$ of a 6 -min test session. Values are expressed as the mean \pm S.E.M. of 8-10 mice. (D) Effects of LPS and KKT on spontaneous locomotor activity. Each mouse was placed individually in a novel cage $(40 \times 25 \times 30 \mathrm{~cm})$ and the distance traveled was analyzed for $60 \mathrm{~min}$. Values are expressed as the mean \pm S.E.M. of 7 mice. ${ }^{*} p<0.05,{ }^{* *} p<0.01 v s$. saline/vehicle-treated mice. ${ }^{\dagger} p<0.05$, ${ }^{\dagger} p<0.01 v s$. LPS/vehicletreated mice. 
A. Hypothalamus
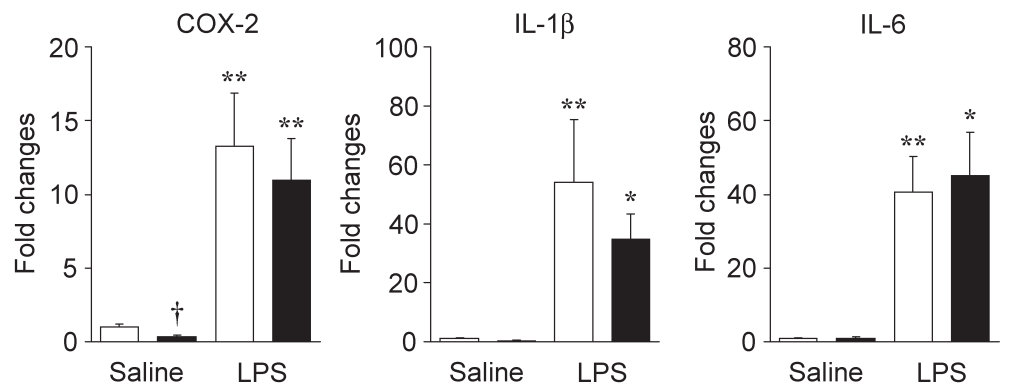

B. Amygdala
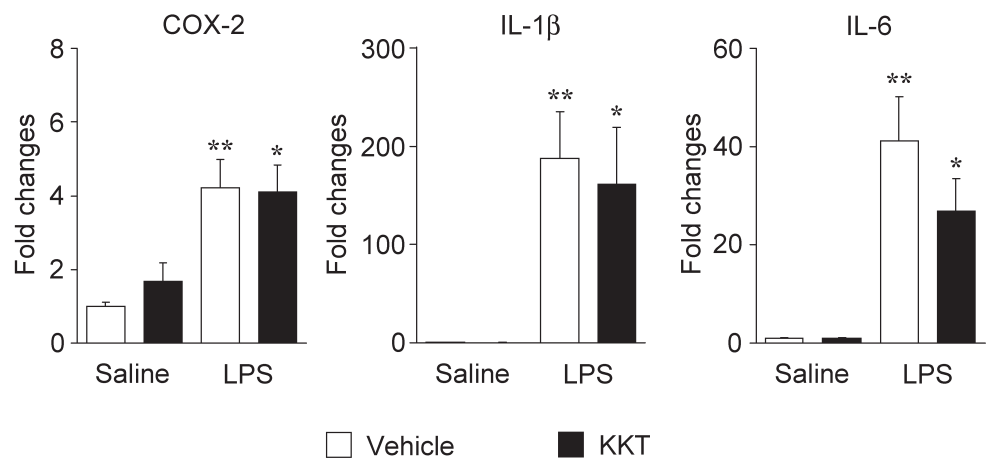

Fig. 2. Effects of KKT on LPS-Induced Increases in mRNAs for Inflammation-Related Genes in the Hypothalamus and Amygdala

Expression levels of COX-2, IL-1 $\beta$ and IL-6 mRNA in the hypothalamus (A) and amygdala (B) are shown as fold changes relative to levels in saline/vehicle-treated mice. Values are expressed as the mean \pm S.E.M. of 6 mice. ${ }^{*} p<0.05,{ }^{* *} p<0.01 v$ s. saline-treated mice. ${ }^{\dagger} p<0.05 v s$. vehicle-treated mice.

between LPS administration and KKT treatment $\left(F_{(1,23)}=0.1\right.$, $p>0.05$ for hypothalamic COX-2; $F_{(1,23)}=0.6, p>0.05$ for hypothalamic IL-1 $\beta ; F_{(1,23)}=0.1, p>0.05$ for hypothalamic IL-6; $F_{(1,23)}=0.5, p>0.05$ for amygdaloid COX-2; $F_{(1,23)}=0.1, p>0.05$ for amygdaloid IL- $\beta ; F_{(1,23)}=1.4, p>0.05$ for amygdaloid IL-6). The increases in mRNA levels for inflammation-related genes were not observed at $24 \mathrm{~h}$ after LPS injection (data not shown).

Effect of KKT on LPS-Induced Neural Activation Involved in Sickness Behavior We previously found that neural activation in the PVN of the hypothalamus and the CeA are likely to be related to LPS-induced sickness behavior. ${ }^{15)}$ Therefore, we examined the effect of KKT on LPS-induced expression of c-Fos, an indirect marker of neural activity, ${ }^{21)}$ in these nuclei at $24 \mathrm{~h}$ after LPS injection. LPS induced significant increases in the number of c-Fos immunopositive cells in the PVN and CeA, and KKT $(300 \mathrm{mg} / \mathrm{kg})$ attenuated these increases $\left(F_{2,15}=14.650, p=0.0003\right.$ for the PVN; $F_{2,15}=33.040$, $p<0.0001$ for the CeA) (Fig. 3).

\section{DISCUSSION}

Previous studies have reported that LPS-induced decreases in spontaneous locomotor activity and food intake are ameliorated within 10-16h, while LPS-induced decreases in novel object exploration and social interaction and an increase in immobility time in the forced swim test remain after $24 \mathrm{~h}^{14,22)}$ Murine colon 26 adenocarcinoma cells-inoculated mice showed sickness behavior such as exploratory behavior deficit, social interaction deficits and depressive-like behavior, whereas locomotor activity and food intake were not affected. ${ }^{23)}$ These findings suggest that decreases in novel object explora- tion and social interaction and an increase in immobility time in the forced swim test can be regarded as common symptoms between two murine experimental models of sickness behavior. In this study, KKT ameliorated the LPS-induced behavioral changes without affecting spontaneous locomotor activity (Fig. 1). We previously showed that KKT ameliorates emotional aspects of sickness behavior in tumor-inoculated mice without affecting spontaneous locomotor activity. ${ }^{21)}$ These results suggest that KKT may have utility for treatment of core symptoms in sickness behavior.

Systemic administration of LPS triggers peripheral innate immune cells to secrete inflammatory cytokines such as IL-1 $\beta$ and IL- $6{ }^{24)}$ These peripheral inflammatory cytokines act on the brain and induce upregulation of inflammatory cytokine production in the CNS, which is associated with sickness behavior. ${ }^{25)}$ In addition, an increase in prostaglandin synthesis through inflammation-induced COX-2 in the CNS is also implicated in sickness behavior. ${ }^{13,22,26,27)}$ We previously reported that genipin, a main constituent of Gardeniae Fructus, is one of the component herbs of KKT, ameliorated LPS-induced sickness behavior and inflammation in the hypothalamus and amygdala $2 \mathrm{~h}$ after LPS administration. ${ }^{15}$ ) Therefore, it seemed likely that KKT would also attenuate LPS-induced inflammation in the hypothalamus and amygdala $2 \mathrm{~h}$ after LPS administration. Contrary to our expectation, KKT tended to decrease mRNA expression for inflammation-related genes in control mice, but did not reverse the LPS-induced increases in mRNA levels in either brain region (Fig. 2). These results suggest that the ameliorative effects of KKT on LPS-induced sickness behavior cannot be explained fully by anti-inflammatory effect.

In rodents, peripheral LPS injection activates several brain nuclei associated with sickness behavior, including the PVN 
A
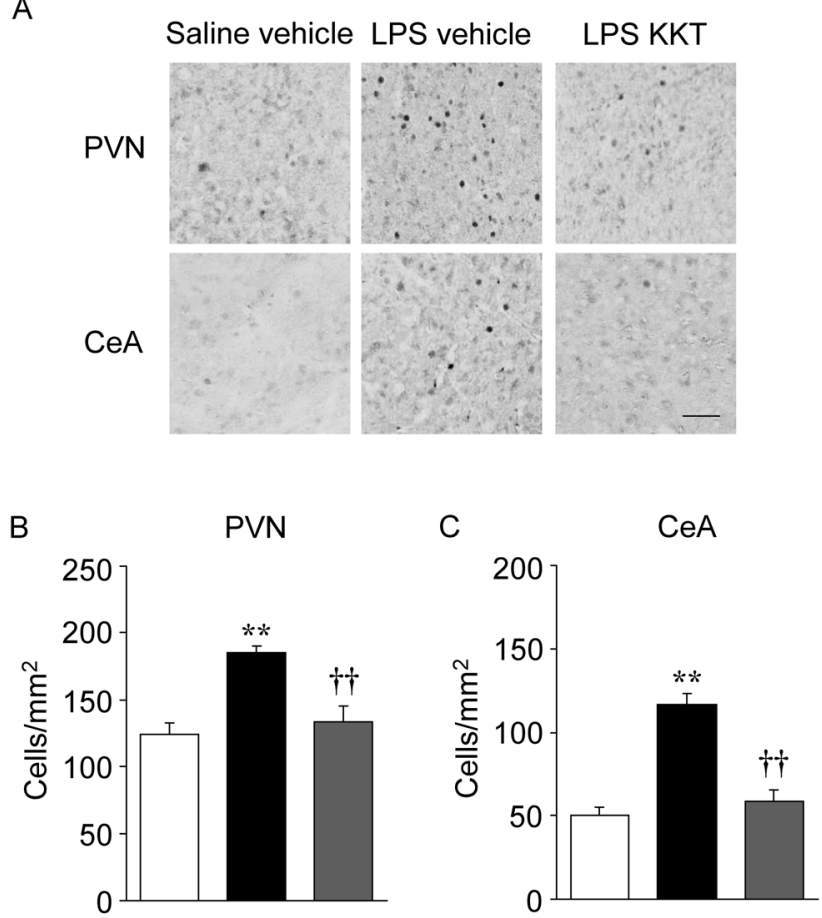

\section{Saline Vehicle $\square$ LPS Vehicle $\square$ LPS KKT}

Fig. 3. Effects of KKT on LPS-Induced Neural Activation in the PVN and $\mathrm{CeA}$

Immunohistochemical localization of the neural activity marker c-Fos was determined $24 \mathrm{~h}$ after LPS administration. (A) Representative photomicrographs showing c-Fos staining in the PVN (top panels) and CeA (bottom panels) in brain sections of mice treated with saline/vehicle (left panels), LPS/vehicle (center panels) and LPS/KKT (right panels). Scale bars, $100 \mu \mathrm{m}$. (B, C) Numbers of c-Fos immunopositive cells in the PVN (B) and CeA (C). Values are expressed as the mean \pm S.E.M. of 6 mice. ${ }^{* *} p<0.01$ vs. saline/vehicle-treated mice. ${ }^{\dagger \dagger} p<0.01$ vs. LPS/vehicle-treated mice.

and $\mathrm{CeA}$, through the vagus nerve and the nucleus of the solitary tract. ${ }^{28,29)}$ We have previously shown that LPS $(500 \mu \mathrm{g} /$ $\mathrm{kg}$, i.p.) increased the number of c-Fos immunopositive cells in the PVN and CeA, and that these increases in c-Fos immunopositive cells were correlated with sickness behavior in ddY mice. ${ }^{15)}$ In this study, we found that KKT reversed the increases in c-Fos immunopositive cells in both the PVN and CeA (Fig. 3), which implies that KKT ameliorates LPS-induced sickness behavior via suppression of immune response-induced neural activation. KKT may attenuate the neural activation by blocking the afferent vagus signals from peripheral sites of inflammation via the vagus nerve. Further studies are needed to clarify the mechanisms through which KKT prevents LPS-induced neural activation.

In conclusion, KKT ameliorated LPS-induced sickness behavior via suppression of neural activation in the PVN and $\mathrm{CeA}$, but had little effect on LPS-induced inflammation. These results indicate that KKT has potential for treatment of sickness behavior. Our findings also suggest that suppression of neural activation in the PVN and CeA is a potential therapeutic approach for treatment of sickness behavior.

Acknowledgment We wish to thank Mr. Ryosuke Yukioka, Ms. Kumi Okamoto and Ms. Yumi Kamikawatoko for their technical assistance.
Conflict of Interest The authors declare no conflict of interest.

Supplementary Materials The online version of this article contains supplementary materials.

\section{REFERENCES}

1) Dantzer R, O'Connor JC, Freund GG, Johnson RW, Kelley KW. From inflammation to sickness and depression: when the immune system subjugates the brain. Nat. Rev. Neurosci., 9, 46-56 (2008).

2) DellaGioia N, Hannestad J. A critical review of human endotoxin administration as an experimental paradigm of depression. Neurosci. Biobehav. Rev., 34, 130-143 (2010).

3) Kronfol Z, Remick DG. Cytokines and the brain: implications for clinical psychiatry. Am. J. Psychiatry, 157, 683-694 (2000).

4) Bluthé RM, Dantzer R, Kelley KW. Effects of interleukin-1 receptor antagonist on the behavioral effects of lipopolysaccharide in rat. Brain Res., 573, 318-320 (1992).

5) Yirmiya R, Tio DL, Taylor AN. Effects of fetal alcohol exposure on fever, sickness behavior, and pituitary-adrenal activation induced by interleukin-1 beta in young adult rats. Brain Behav. Immun., 10, 205-220 (1996).

6) Swiergiel AH, Smagin GN, Johnson LJ, Dunn AJ. The role of cytokines in the behavioral responses to endotoxin and influenza virus infection in mice: effects of acute and chronic administration of the interleukin-1-receptor antagonist (IL-1ra). Brain Res., 776, 96-104 (1997)

7) Bluthé RM, Castanon N, Pousset F, Bristow A, Ball C, Lestage J, Michaud B, Kelley KW, Dantzer R. Central injection of IL-10 antagonizes the behavioural effects of lipopolysaccharide in rats. Psychoneuroendocrinology, 24, 301-311 (1999).

8) Bluthé RM, Laye S, Michaud B, Combe C, Dantzer R, Parnet P. Role of interleukin-lbeta and tumour necrosis factor-alpha in lipopolysaccharide-induced sickness behaviour: a study with interleukin-1 type I receptor-deficient mice. Eur. J. Neurosci., 12, 4447-4456 (2000).

9) Bluthé RM, Michaud B, Poli V, Dantzer R. Role of IL-6 in cytokine-induced sickness behavior: a study with IL-6 deficient mice. Physiol. Behav., 70, 367-373 (2000).

10) Dunn AJ, Swiergiel AH. Effects of interleukin-1 and endotoxin in the forced swim and tail suspension tests in mice. Pharmacol. Biochem. Behav., 81, 688-693 (2005).

11) Frenois F, Moreau M, O’Connor J, Lawson M, Micon C, Lestage J, Kelley KW, Dantzer R, Castanon N. Lipopolysaccharide induces delayed FosB/DeltaFosB immunostaining within the mouse extended amygdala, hippocampus and hypothalamus, that parallel the expression of depressive-like behavior. Psychoneuroendocrinology, 32, 516-531 (2007).

12) Henry CJ, Huang Y, Wynne A, Hanke M, Himler J, Bailey MT, Sheridan JF, Godbout JP. Minocycline attenuates lipopolysaccharide (LPS)-induced neuroinflammation, sickness behavior, and anhedonia. J. Neuroinflammation, 5, 15 (2008).

13) de Paiva VN, Lima SN, Fernandes MM, Soncini R, Andrade CA, Giusti-Paiva A. Prostaglandins mediate depressive-like behaviour induced by endotoxin in mice. Behav. Brain Res., 215, 146-151 (2010).

14) Haba R, Shintani N, Onaka Y, Wang H, Takenaga R, Hayata A, Baba A, Hashimoto H. Lipopolysaccharide affects exploratory behaviors toward novel objects by impairing cognition and/or motivation in mice: Possible role of activation of the central amygdala. Behav. Brain Res., 228, 423-431 (2012).

15) Araki R, Hiraki Y, Yabe T. Genipin attenuates lipopolysaccharideinduced persistent changes of emotional behaviors and neural activation in the hypothalamic paraventricular nucleus and the central amygdala nucleus. Eur. J. Pharmacol., 741, 1-7 (2014). 
16) Nishizawa K, Saito H, Nishiyama N. Effects of Kamikihi-to, a traditional Chinese medicine, on passive and conditioned avoidance performance impairment in senescence accelerated mouse (SAM). Jpn. J. Pharmacol., 54, 375-382 (1990).

17) Shimamura M, Nishizawa K, Yamashita A. Effects of Kamikihi-to on ovariectomy-induced changes in behavior and circulation in rats. Nihon Yakurigaku Zasshi. Folia Pharmacologica Japonica, 108, 65-75 (1996).

18) Nishizawa K, Yamashita A. Effects of Kamikihi-to, a traditional Chinese medicine, on behavioral changes induced by methyl-betacarboline-3-carboxylate in mice and rats. Jpn. J. Pharmacol., 75, 391-397 (1997).

19) Egashira N, Manome N, Kurauchi K, Matsumoto Y, Iwasaki K, Mishima K, Shoyama Y, Fujiwara M. Kamikihi-to, a Kampo medicine, ameliorates impairment of spatial memory in rats. Phytotherapy Research: PTR, 21, 126-129 (2007).

20) Tohda C, Nakada R, Urano T, Okonogi A, Kuboyama T. Kamikihito (KKT) rescues axonal and synaptic degeneration associated with memory impairment in a mouse model of Alzheimer's disease, 5XFAD. Int. J. Neurosci., 121, 641-648 (2011).

21) Dragunow M, Faull R. The use of c-fos as a metabolic marker in neuronal pathway tracing. J. Neurosci. Methods, 29, 261-265 (1989).

22) Haba R, Shintani N, Onaka Y, Kanoh T, Wang H, Takenaga R, Hayata A, Hirai H, Nagata KY, Nakamura M, Kasai A, Hashimoto R, Nagayasu K, Nakazawa T, Hashimoto H, Baba A. Central CRTH2, a second prostaglandin D2 receptor, mediates emotional impairment in the lipopolysaccharide and tumor-induced sickness behavior model. The Journal of Neuroscience: The Official Journal of the Society for Neuroscience, 34, 2514-2523 (2014).

23) Araki R, Nishida S, Hiraki Y, Yabe T. Kamikihito ameliorates tumor-induced sickness behavior in mice. Traditional \& Kampo Medicine, 2, 93-96 (2015).

24) Kent S, Bluthe RM, Dantzer R, Hardwick AJ, Kelley KW, Rothwell NJ, Vannice JL. Different receptor mechanisms mediate the pyrogenic and behavioral effects of interleukin 1. Proc. Natl. Acad. Sci. U.S.A., 89, 9117-9120 (1992).

25) Nguyen MD, Julien JP, Rivest S. Innate immunity: the missing link in neuroprotection and neurodegeneration? Nat. Rev. Neurosci., 3, 216-227 (2002).

26) Naoi K, Kogure S, Saito M, Hamazaki T, Watanabe S. Differential effects of selective cyclooxygenase (COX)-1 and COX-2 inhibitors on anorexic response and prostaglandin generation in various tissues induced by zymosan. Biol. Pharm. Bull., 29, 1319-1324 (2006).

27) Pecchi E, Dallaporta M, Jean A, Thirion S, Troadec JD. mPGES-1 knock-out mice are resistant to cancer-induced anorexia despite the absence of central mPGES-1 up-regulation in wild-type anorexic mice. J. Neuroimmunol., 199, 104-114 (2008).

28) Konsman JP, Luheshi GN, Bluthé RM, Dantzer R. The vagus nerve mediates behavioural depression, but not fever, in response to peripheral immune signals; a functional anatomical analysis. Eur. J. Neurosci., 12, 4434-4446 (2000).

29) Marvel FA, Chen CC, Badr N, Gaykema RP, Goehler LE. Reversible inactivation of the dorsal vagal complex blocks lipopolysaccharide-induced social withdrawal and c-Fos expression in central autonomic nuclei. Brain Behav. Immun., 18, 123-134 (2004). 